\title{
Validation of the 8th lung cancer TNM classification and clinical staging system in a German cohort of surgically resected patients
}

https://doi.org/10.1515/iss-2020-0010

Received March 23, 2020; accepted May 20, 2020; published online August 12, 2020

\section{Abstract}

Objectives: The updated 8th edition of the tumor, node, metastases (TNM) classification system for non-small cell lung cancer (NSCLC) attempts to improve on the previous 7 th edition in predicting outcomes and guiding management decisions. This study sought to determine whether the 8th edition was more accurate in predicting long-term survival in a European population of surgically treated NSCLC patients.

Methods: We scanned the archives of the Heckeshorn Lung Clinic for patients with preoperative clinical stages of IIIA or lower (based on the 7th edition), who received surgery for NSCLC between 2009 and 2014. We used pathologists' reports and data on tumor size and location to reassign tumor stages according to the 8th edition. We then analyzed stage specific survival and compared the accuracy of the two systems in predicting long-term survival. We excluded patients with neoadjuvant treatment, incomplete follow-up data, tumor histologies other than NSCLC, or death within 30 days of surgery.

Results: The final analysis included 1,013 patients. Overall five-year survival was $47.3 \%$. The median overall survival (OS) was 63 months (range 1-222), and the median diseasefree survival (DFS) was 50 months (0-122). The median follow-up time for non-censored patients was 84 months (range 60-122).

Conclusions: We found significant survival differences between the newly defined stages 1A1, 1A2 and 1A3 (previously $1 \mathrm{~A})$. We also found that the 8 th edition of TMN

\footnotetext{
*Corresponding author: Joachim Pfannschmidt, M.D., Ph.D, Department of Thoracic Surgery, Heckeshorn Lung Clinic HELIOS Klinikum Emil von Behring, Walterhöferstr. 11, D-14165, Berlin, Germany, Phone: +49 308102 2248,

E-mail: joachim.pfannschmidt@helios-gesundheit.de

Samantha Taber: Department of Thoracic Surgery, Heckeshorn Lung Clinic-HELIOS Klinikum Emil von Behring, Berlin, Germany,

E-mail: samanta.taber@helios-gesundheit.de
}

classification was a significantly better predictor of longterm survival, compared to the 7th edition.

Keywords: lung cancer; NSCLC; prognosis; staging; thoracic surgery; TNM; validation.

\section{Introduction}

The tumor, node, and metastasis (TNM) classification scheme for non-small cell lung cancer (NSCLC) aims to provide a standardized means of describing the anatomic extent of the cancer at time of diagnosis. It is important for individual patients and clinicians in determining prognosis and appropriate course of treatment [1]. It also has a role in facilitating communication between clinicians and researchers from different disciplines and geographical locations. Although this requires a certain degree of stability in the nomenclature, the Union for International Cancer Control (UICC), which oversees the TNM classification system internationally, periodically makes updates to reflect developments in technology and understanding of tumor behavior [2].

The most recent 8th edition of the TNM classification system has been in effect since January 2017 [3]. Although the update includes modifications to both the $\mathrm{T}$ and $\mathrm{M}$ descriptors [4], for patients under consideration for surgery (nearly $85 \%$ of the database) [5], the T descriptor is of primary interest. The 8th edition changes cause a small proportion of patients to be assigned a lower $\mathrm{T}$ category (based on tumor atelectasis, involvement of the main bronchus, or invasion of the mediastinal pleura). For the majority of patients, however, the changes in the 8th edition result in a higher T category and consequently a higher UICC stage. Based on the idea that every centimeter of tumor size affects prognosis, the $\mathrm{T}$ descriptor for the smallest tumors (stage IA in the 7th edition) has been further differentiated into stages IA1 (T1mi or 1a NOM0), IA2 (T1b NOM0) and IA3 (T1c NOM0). Moreover, tumors $4 \mathrm{~cm}$ and greater may now be assigned a higher T category than previously [6].

The UICC recommendations are based on a series of analyses performed by the International Association for the Study of Lung Cancer (IASLC) [4-8] and are based on an 
international database of nearly 80,000 patients [2]. The 8th edition was externally validated in a large study of North American patients from the National Cancer Data Base [9]. The original database, however, drew a disproportionate number of patients from Asia (specifically Japan), and most other existing validation studies for surgically treated patients, are based on Asian populations [10-13]. This is significant in light of the known tumor biological and prognostic differences between Asian and Caucasian populations $[14,15]$. Even within the IASLC database, early stages of NSCLC seem to predominate within Asian populations, while advanced stages are more prevalent in European populations [5]. Validation studies of the 8th edition of the TNM classification scheme in European populations are limited $[16,17]$. The object of this study is to determine whether the 8th edition is more accurate than the 7th edition in predicting long-term outcome in a Germany-based population of surgically treated NSCLC patients.

\section{Methods}

We retrospectively scanned the archives of the Heckeshorn Lung Clinic in Berlin, Germany for patients who had undergone lung resection for NSCLC between January 2009 and June 2014. Data on these patients had been collected for purposes of internal quality control, and all patients had given their informed written consent for their data to be used in future research projects. For this reason the institutional review board waived the requirement for registration.

All patients included had preoperative clinical stages of IIIA (T1aT2b N2M0 or T3-T4 N1M0 or T4 NOM0) or lower (based on the 7th edition, with some cases of postoperative pathology-based upstaging to stage IIIB). We excluded patients with neoadjuvant treatment, death within 30 days of surgery, tumor histology other than NSCLC, or incomplete follow-up data.

Preoperative evaluation included detailed medical history, physical examination, positron emission tomography CT (PET-CT), and pulmonary function tests. Cranial CT or cranial MRT were only performed when symptoms suggestive of cerebral metastases were present. All patients received surgery in curative intent. Based on local tumor board consensus, selected patients also received adjuvant chemotherapy, radiation therapy, or combined radiochemotherapy.

All resected tissues, including lymph nodes, were examined by a board-certified pathologist and assigned a tumor stage based on the 7th edition TNM classification for NSCLC. We retrospectively extracted the data on tumor size and location from pathologists' reports and reassigned each patient new TNM and UICC stages based on the 8th edition guidelines.

Overall survival time (OS) was defined as date of surgery until either the date of death (from any cause) or the date when the patient was last known to be alive. Disease free survival (DFS) was defined as date of surgery until date of tumor recurrence. Patients were followedup with physical examination and chest CT, first biannually and after two years, annually. In-hospital follow-up data was supplemented with reports from external physicians and information from the local residents' registration office. Patients with no known date of death, for whom data was not available for at least five years post-surgery, were considered lost to follow-up and were excluded from the analysis. Patients known to be alive at the end of the five-year follow-up period were censored. In cases where patients received a second surgery for recurrent lung cancer, only the date of the initial surgery was included in the analysis for determining OS and DFS.

Finally, we retrospectively extracted additional patient data on age, gender, tumor histology, extent of surgical resection, tumor resection margins, and anatomic location.

\section{Statistical analysis}

All statistical analyses were performed using SPSS statistics for Windows, V.20 (IBM Corp). After reclassifying tumor stage according to the 8th edition of the TNM system, we generated Kaplan-Meier survival curves for each tumor stage, based on both the 7 th and the 8 th edition classification systems. We used log-rank tests determine whether the observed differences in survival curves were significant. We also evaluated potentially confounding factors (age, sex, tumor histology, extent of surgery, tumor resection margins) for significance using Chisquared and Mann-Whitney tests and included those where $\mathrm{p}<0.05$ in the Cox regression analysis. After determining the significant independent variables, we performed additional analyses of the differences in neighboring survival curves to adjust for these covariates. Finally, we determined the $\mathrm{R}^{2}$ measure, as recommended by the IASLC, as a means of assessing the discriminative ability of the respective models [18].

\section{Results}

We initially identified 1,272 patients, who were operated on in curative intent for expected NSCLC. 55 patients were excluded for neoadjuvant treatment, and 23 were excluded for perioperative mortality (death within 30 days of surgery). 64 patients were excluded after the lesion in question turned out to be an entity other than NSCLC, and 117 were excluded for incomplete follow-up. 1,013 patients could be included in the final analysis, as is illustrated visually in Figure 1.

The baseline characteristics of the cohort are summarized in Table 1.479 patients (47.3\%) were censored (alive at the end up of a minimum follow-up period of 60 months). Among censored patients the median followup time was 84 months (range 60-122). For the cohort as a whole, median OS was 63 months (range 1-122), and median DFS was 50 months (range 0-122). The median age was 67 years (range 39-87), and males accounted for $58.4 \%$ of the study population ( $\mathrm{n}=592)$. Adenocarcinoma appeared most frequently (51.7\%), followed by squamous cell carcinoma (35.0\%). Lobectomy or bilobectomy was the most frequently performed surgical procedure (79.2\%). Pneumonectomies accounted for $7.8 \%$ of cases, while 


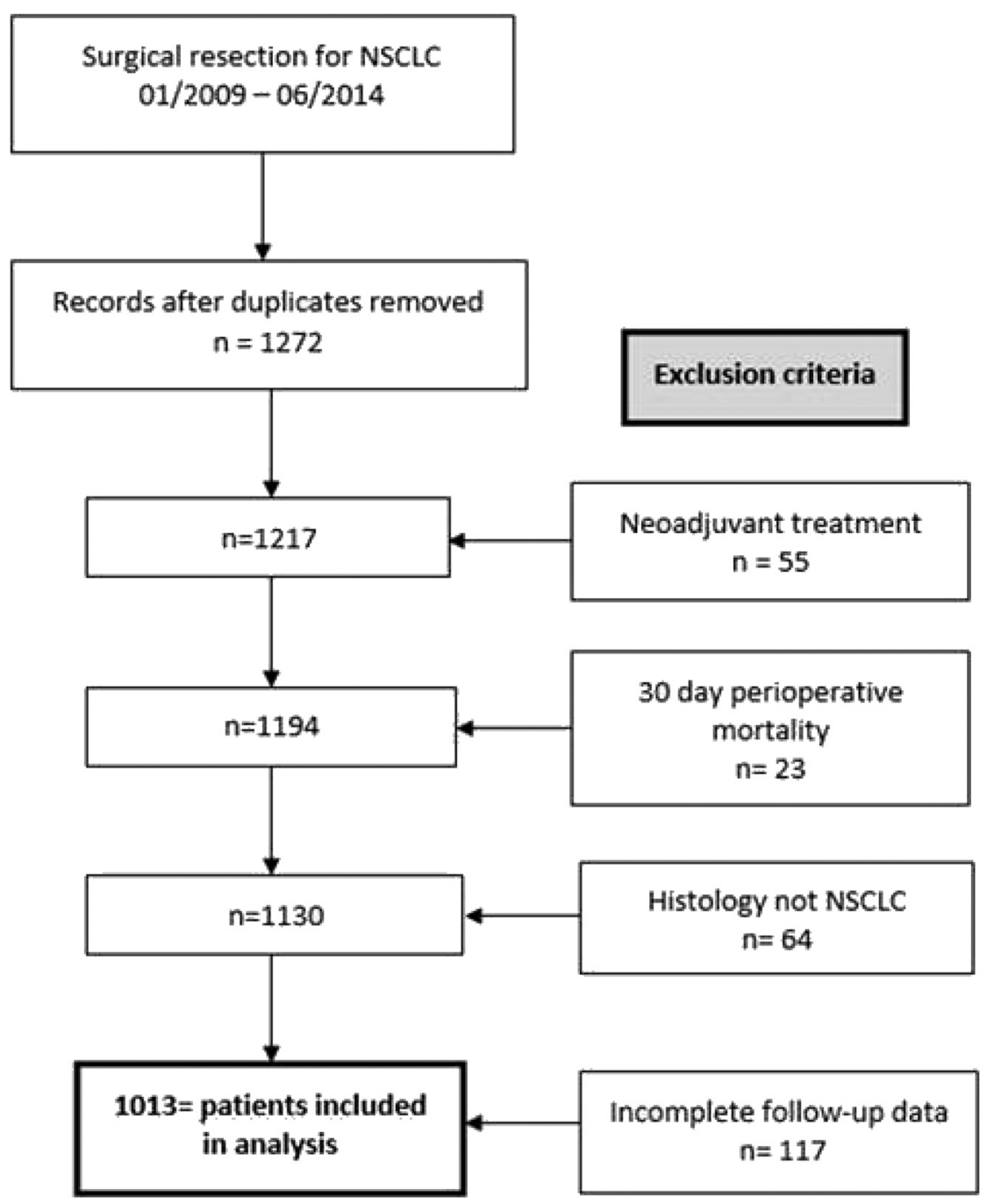

Figure 1: Flow-chart demonstrating patient selection; NSCLC $=$ non-small cell lung cancer.

anatomical segmental resections $(7.7 \%)$ and atypical wedge resections (5.5\%) accounted for the rest. The median tumor diameter was $3.5 \mathrm{~cm}$ (IQR $2.0-5.4 \mathrm{~cm}$ ). In most cases a tumor-free resection margin was possible (94.7\%). 297 patients (29.3\%) received some form of adjuvant treatment (chemotherapy: $n=182$, radiation: $n=29$, combined radiochemotherapy: $n=86$ ).

Tumor stage distribution within the cohort, based on the 7th and 8th TNM editions respectively, is presented in Table 2. Of the 294 patients in stage IA (T1a or T1b NOM0) in the 7th edition, only 34 (3.4\%) qualified for stage IA1 (T1a NOMO) in the 8th edition. The remaining patients in stage IA (7th edition) were reassigned to either stages IA2 (T1b NOMO) or IA3 (T1C NOMO) in the 8th edition. Further reassigning of stages resulted in a net shift of patients to higher tumor stages, as is presented in Table 2. A total of 341 patients $(33.7 \%)$ were shifted to a higher tumor stage (due to tumor size). Only 11 patients (1.1\%) were downstaged due to distance from carina or mediastinal pleural invasion.

The results of the univariate analysis with respective p-values appear in Table 3. Here we determined that male gender, surgery other than lobectomy/bilobectomy, positive tumor resection margins, age $>65$ years, and higher tumor stage (both 7th and 8th editions) were associated with worse five-year OS and DFS. Tumor histology and side (left vs. right) were not significant. In the multivariate Cox regression analysis we found that male gender, age $>65$ years, segmentectomy/wedge resection vs. lobectomy, and increasing tumor stage were significant independent predictors of both worse OS and DFS. Increasing tumor stage, for both the 7th and 8th TNM editions, was associated with worse OS and DFS. These results are summarized in Table 4. 7th edition had an $\mathrm{R}^{2}$ of 0.142 ; the model based on the 8th edition had an $R^{2}$ of 0.153 . For DFS, the $R^{2}$ values for the models based on the 7 th and 8 th editions were 0.128 and 
Table 1: Baseline characteristics of study population.

\begin{tabular}{|c|c|}
\hline Variable & Value \\
\hline \multicolumn{2}{|l|}{ Gender } \\
\hline Male & $592(58.4 \%)$ \\
\hline Female & $421(41.6 \%)$ \\
\hline \multicolumn{2}{|l|}{ Histology } \\
\hline Adeno & $524(51.7 \%)$ \\
\hline Squamous & $355(35.0 \%)$ \\
\hline Large cell & $86(8.5 \%)$ \\
\hline Other (NSCLC) & $48(4.7 \%)$ \\
\hline \multicolumn{2}{|l|}{ Age (years) } \\
\hline$\leq 65$ & $443(43.7 \%)$ \\
\hline$>65$ & $570(56.3 \%)$ \\
\hline \multicolumn{2}{|l|}{ Age (years) } \\
\hline Median (range) & $67(39-87)$ \\
\hline \multicolumn{2}{|l|}{ Operation } \\
\hline (Bi-)lobectomy & $802(79.2 \%)$ \\
\hline Pneumonectomy & 79 (7.8\%) \\
\hline Segmentectomy & $78(7.7 \%)$ \\
\hline Wedge resection & $54(5.3 \%)$ \\
\hline \multicolumn{2}{|l|}{ Resection margins } \\
\hline Ro & 959 (94.7\%) \\
\hline $\mathrm{R} 1, \mathrm{R} 2, \mathrm{RX}$ & $54(5.3 \%)$ \\
\hline \multicolumn{2}{|l|}{ Side } \\
\hline Left & $430(42.5 \%)$ \\
\hline Right & $583(57.6 \%)$ \\
\hline \multicolumn{2}{|l|}{ OS (months) } \\
\hline Median (IQR) & $63(1-122)$ \\
\hline \multicolumn{2}{|l|}{ DFS (months) } \\
\hline Median (IQR) & $50(0-122)$ \\
\hline \multicolumn{2}{|c|}{ Tumor diameter $(\mathrm{cm})$} \\
\hline Median (IQR) & $3.5(2.0-5.4)$ \\
\hline Censored (OS) & 479 (47.3\%) \\
\hline Censored (DFS) & $368(36.3 \%)$ \\
\hline \multicolumn{2}{|c|}{ Follow up censored (months) } \\
\hline Median (range) & $84(60-122)$ \\
\hline
\end{tabular}

$\mathrm{NSCLC}=$ non-small cell lung cancer, $I \mathrm{QR}=$ interquartile range, OS = overall survival, DFS = disease free survival.
0.135 respectively, suggesting that the $8^{\text {th }}$ edition makes for a marginally better predictive model.

Figure 2 shows the survival curves for OS and DFS according to UICC tumor stage for both the 7th and 8th TNM editions respectively. We observed stepwise deterioration with increasing pathologic stage. In the initial log-rank analysis, not all differences in adjacent survival curves were significant (Figure 2), but after adjusting for the significant predictors identified in the initial Cox regression analysis (age, surgery, and gender), the differences between all neighboring stages were significant, as is presented in Table 5.

\section{Discussion}

In contrast to many tumor classification systems, the TNM staging system for NSCLC is not based on consensus and expert opinion but on an extensive international database and a series of complex statistical analyses. Despite these efforts, the IASLC's most recent 8th edition draws a disproportionate amount of data from Asia and from Japan specifically [18], raising questions about the applicability to non-Asian populations. Moreover, most existing validation studies are based on Asian populations. This study attempts to determine how well the 8th edition of the TNM classification system predicts long-term outcome in a European population of surgically treated NSCLC patients.

The primary finding of this study is that the revised 8th edition TNM is more accurate at predicting long-term OS and DFS than the previous 7th edition. The improvements, however, are small and may not apply equally to all tumor stages. The integrated predictive models that included both tumor stage and covariates were slightly better at

Table 2: Changes in distribution based on 7th and 8th editions of TNM classification.

\begin{tabular}{|c|c|c|c|c|c|c|c|}
\hline \multirow[t]{2}{*}{ UICC stage based on 8th TNM } & \multirow[b]{2}{*}{ IA } & \multirow[b]{2}{*}{ IB } & \multirow[b]{2}{*}{ IIA } & \multirow[b]{2}{*}{ IIB } & \multicolumn{3}{|c|}{ UICC stage based on 7th TNM } \\
\hline & & & & & IIIA & IIIB & Total (\%) \\
\hline IA1 (T1aN0M0) & 34 & 0 & 0 & 0 & 0 & 0 & $34(3.36 \%)$ \\
\hline IA2 (T1bNOM0) & 155 & 0 & 0 & 0 & 0 & 0 & $155(15.3 \%)$ \\
\hline IA3 (T1CNOM0) & 105 & 0 & 0 & 0 & 0 & 0 & $105(10.4 \%)$ \\
\hline IB (T2aNOM0) & 0 & 112 & 0 & 0 & 0 & 0 & $112(11.1 \%)$ \\
\hline IIA (T2bNOM0) & 0 & 67 & 24 & 0 & 0 & 0 & $91(8.98 \%)$ \\
\hline IIB (T1a-T2bN1M0, T3N0M0) & 0 & 0 & 121 & 51 & 0 & 0 & $172(17.0 \%)$ \\
\hline IIIA (T1a-T2bN2M0, T3-4N1 or T4NOMO) & 0 & 0 & 0 & 83 & 167 & 0 & $250(24.7 \%)$ \\
\hline IIIB (T1a-T2bN3M0, T3-4N2M0) & 0 & 0 & 0 & 0 & 70 & 24 & $94(9.3 \%)$ \\
\hline Total (\%) & $294(29.0 \%)$ & $179(17.7 \%)$ & $145(14.3 \%)$ & $134(13.2 \%)$ & $237(23.4 \%)$ & $24(2.37 \%)$ & \\
\hline
\end{tabular}

UICC = Union for International Cancer Control. 
Table 3: Univariate analysis of potential outcome factors.

\begin{tabular}{|c|c|c|c|c|}
\hline \multirow[t]{2}{*}{ Variable } & \multicolumn{2}{|c|}{ five-year OS } & \multicolumn{2}{|c|}{ five-year DFS } \\
\hline & $\%$ & p-Value & $\%$ & p-Value \\
\hline Side & & 0.144 & & 0.456 \\
\hline Left & 50.0 & & 37.7 & \\
\hline Right & 45.4 & & 35.4 & \\
\hline Gender & & $<0.001$ & & $<0.001$ \\
\hline Male & 41.6 & & 31.4 & \\
\hline Female & 55.3 & & 43.2 & \\
\hline Histology & & 0.295 & & 0.421 \\
\hline Adeno & 47.9 & & 37.0 & \\
\hline Squamous & 47.0 & & 34.9 & \\
\hline Large cell & 39.5 & & 32.6 & \\
\hline Other NSC & 56.3 & & 45.8 & \\
\hline Surgery & & $<0.001$ & & $<0.001$ \\
\hline (Bi-)lobectomy & 51.1 & & 39.5 & \\
\hline Pneumonectomy & 43.0 & & 35.4 & \\
\hline Segment & 26.9 & & 19.2 & \\
\hline Wedge & 25.9 & & 14.8 & \\
\hline Resection margins & & 0.005 & & 0.008 \\
\hline Ro & 48.5 & & 37.4 & \\
\hline $\mathrm{R} 1, \mathrm{R} 2, \mathrm{RX}$ & 26.4 & & 9.0 & \\
\hline UICC 7 & & $<0.001$ & & $<0.001$ \\
\hline IA & 57.1 & & 43.2 & \\
\hline IB & 54.2 & & 43.0 & \\
\hline IIA & 55.2 & & 40.7 & \\
\hline IIB & 45.5 & & 32.8 & \\
\hline IIIA & 30.0 & & 24.9 & \\
\hline IIIB & 8.3 & & 8.3 & \\
\hline UICC 8 & & $\mathrm{p}<0.001$ & & $\mathrm{p}<0.001$ \\
\hline IA1 & 73.5 & & 61.8 & \\
\hline $\mathrm{IA} 2$ & 54.8 & & 40.7 & \\
\hline IA3 & 55.2 & & 41.0 & \\
\hline IB & 57.1 & & 50.0 & \\
\hline IIA & 52.8 & & 40.7 & \\
\hline IIB & 52.3 & & 39.0 & \\
\hline IIIA & 36.4 & & 28.0 & \\
\hline IIIB & 19.2 & & 18.1 & \\
\hline
\end{tabular}

OS = overall survival; DFS = disease free survival; UICC = Union for International Cancer Control.

predicting OS and DFS (based on $\mathrm{R}^{2}$ values) when incorporating 8th edition stages rather than 7 th edition stages. Sui et al. also found that the 8th edition made for somewhat better predictive models $\left(R^{2}=0.172\right.$ vs. 0.162 for $O S ; R^{2}=0.183$ vs. 0.178 for DFS) [11], and most other validation studies came to similar conclusions [11-13, 19]. Only Jung et al., analyzing the $\mathrm{T}$ descriptor changes in a Korean population $(n=1,316)$, did not find any difference [10]. Interestingly, the findings of the other European studies we identified were less conclusive. Blaauwgeers et al. ( $n=683$, Netherland) only included patents with pT3 pNO tumors and found that the 8th edition was only a better predictor for certain tumor constellations [17]. Neppl et al. ( $\mathrm{n}=354$, Switzerland) found that the $8^{\text {th }}$ edition was slightly better at predicting long- term outcome but only in patients with squamous cell carcinomas [16].

After adjusting for covariates, all neighboring tumor stages showed significant deterioration in both OS and DFS with increasing tumor stage (Table 5). Of our observed survival curves, the outcome differences between the newly created 8th edition stages IA1 and IA2 is perhaps most noteworthy (hazard ratio: IA1 vs. IA2 $=0.42$ for OS; hazard ratio: IA1 vs. IA2 $=0.55$ for DFS). Even before adjusting for covariates, in comparing stages IA1 and IA2 we observed a significant difference for $\mathrm{OS}(\mathrm{p}=0.039)$ and a trend for DFS ( $\mathrm{p}=0.08$ ), supporting the notion that even in very early stages small size differences can matter. Chen et al. found that the survival curve differences were only significant for stages IA1 vs IA2 and for stages IA2 vs IA3 [12]. In our study the prognostic differences between stages IA2 through IIA (T2b NOM0) were less pronounced, but we observed a clear drop in survival rates (OS and DFS) going from stage IIB (T1a-T2b N1M0 or T3 NOM0) to IIIA (T1a-T2b N2MO or T3-2 N1MO or T4 NOM0), and from stage IIIA to IIIB (T1a-T3 N3M0 or T4 N2) (Figure 2).

In initial discussions and validation analyses the 7th edition was criticized for having too few patients in stage IIB [20, 21]. The 8th edition changes regarding tumor size result in the upstaging of tumors previously classified as stage IIA to stage IIB. In our study the proportion of patients in stage IIB grew from 13 to $16 \%$, while the proportion in stage IIA (Tumor 4-5 cm, no affected lymph nodes) decreased from 14 to $9 \%$. Sui et al. reported that after reclassifying according to the 8 th edition, the proportion of stage IIA tumors decreased to $5.5 \%[7,11]$.

Perhaps more importantly, the revisions to the 8th edition mean that patients with tumors greater than $4 \mathrm{~cm}$ $(\leq 5 \mathrm{~cm}$, no nodal metastases), are upstaged from stage IB to stage IIA. These shifts may affect decisions to recommend adjuvant chemotherapy or not. In our study this applied to 67 patients, who were retrospectively upstaged to stage IIA and may have been offered adjuvant chemotherapy if diagnosed and staged today on the basis of the 8th edition. It is unclear, however, whether this subset of patients benefits from adjuvant chemotherapy or not [22-24].

The other critical shift is from stage IIIA to IIIB. Apart from a small proportion of cases that are downstaged from $\mathrm{T} 3$ to $\mathrm{T} 2$ on the basis of tumor atelectasis, carina proximity or invasion of the mediastinal pleura, most 8th edition shifts are upward from stage IIIA to IIIB, for patients with $\mathrm{N} 2$ lymph nodes and tumors larger than $4 \mathrm{~cm}$. Our cohort contained 70 such patients with 7 th edition stage IIIA tumors that were retrospectively upstaged to stage IIIB. It is unclear whether these patients would have been offered surgery if diagnosed today, although decisions to perform 
Table 4: Results from the Cox regression analysis for OS and DFS according to 7th and 8th TNM classifications.

\begin{tabular}{|c|c|c|c|c|c|c|c|}
\hline \multicolumn{4}{|l|}{ OS based on 7th TNM } & \multicolumn{4}{|c|}{ DFS based on 7th TNM } \\
\hline Variable & p-Value & HR & $95 \% \mathrm{Cl}$ & Variable & p-Value & HR & $95 \% \mathrm{Cl}$ \\
\hline Gender & & & & Gender & & & \\
\hline Male & Reference & & & Male & Reference & & \\
\hline Female & $<0.001$ & 0.79 & $0.72-0.87$ & Female & $<0.001$ & 0.86 & $0.79-0.93$ \\
\hline Age & & & & Age & & & \\
\hline$\leq 65$ years & Reference & & & $\leq 65$ years & Reference & & \\
\hline$>65$ years & $<0.001$ & 1.22 & $1.11-1.33$ & $>65$ years & $<0.001$ & 1.20 & $1.11-1.30$ \\
\hline Surgery & & & & Surgery & & & \\
\hline (Bi-)lobectomy & Reference & & & (Bi-)lobectomy & Reference & & \\
\hline Pneumonectomy & $<0.001$ & 0.66 & $0.51-0.86$ & Pneumonectomy & $<0.001$ & 0.67 & $0.53-0.86$ \\
\hline Segmentectomy & $<0.001$ & 1.30 & $1.01-1.58$ & Segmentectomy & 0.116 & 1.19 & $0.96-1.48$ \\
\hline Wedge resection & $<0.001$ & 1.52 & $1.17-1.98$ & Wedge resection & $<0.001$ & 1.58 & $1.24-2.02$ \\
\hline UICC 7 & & & & UICC 7 & & & \\
\hline Stage IA & Reference & & & Stage IA & Reference & & \\
\hline Stage IB & $<0.001$ & 0.68 & $0.55-0.83$ & Stage IB & $<0.001$ & 0.69 & $0.57-0.84$ \\
\hline Stage IIA & $<0.001$ & 0.67 & $0.53-0.84$ & Stage IIA & $<0.001$ & 0.68 & $0.56-0.83$ \\
\hline Stage IIB & 0.29 & 0.89 & $0.72-1.10$ & Stage IIB & 0.628 & 0.95 & $0.78-1.16$ \\
\hline Stage IIIA & $<0.001$ & 1.62 & $1.38-1.92$ & Stage IIIA & $<0.001$ & 1.53 & $1.31-1.79$ \\
\hline Stage IIIB & $<0.001$ & 2.53 & $1.75-3.67$ & Stage IIIB & $<0.001$ & 2.20 & $1.52-3.16$ \\
\hline OS based on 8th TNM & & & & DFS based on 8th & & & \\
\hline Gender & & & & Gender & & & \\
\hline Male & Reference & & & Male & Reference & & \\
\hline Female & $<0.001$ & 0.80 & $0.73-0.88$ & Female & $<0.001$ & 0.86 & $0.79-0.93$ \\
\hline Age & & & & Age & & & \\
\hline$\leq 65$ years & Reference & & & $\leq 65$ years & Reference & & \\
\hline$>65$ years & $<0.001$ & 1.21 & $1.11-1.33$ & $>65$ years & $<0.001$ & 1.19 & $1.1-1.3$ \\
\hline Surgery & & & & Surgery & & & \\
\hline (Bi-)lobectomy & Reference & & & (Bi-)lobectomy & Reference & & \\
\hline Pneumonectomy & $<0.001$ & 0.62 & $0.48-0.80$ & Pneumonectomy & $<0.001$ & 0.63 & $0.49-0.81$ \\
\hline Segmentectomy & 0.013 & 1.34 & $1.06-1.69$ & Segmentectomy & 0.04 & 1.26 & $1.01-1.57$ \\
\hline Wedge resection & $<0.001$ & 1.63 & $1.25-2.11$ & Wedge resection & $<0.001$ & 1.65 & $1.30-2.10$ \\
\hline UICC 8 & & & & $\operatorname{UICC} 8$ & & & \\
\hline Stage IA1 & Reference & & & Stage IA1 & Reference & & \\
\hline Stage IA2 & 0.08 & 0.81 & $0.64-1.03$ & Stage IA2 & 0.04 & 0.81 & $0.66-0.99$ \\
\hline Stage IA3 & 0.21 & 0.84 & $0.64-1.11$ & Stage IA3 & 0.31 & 0.88 & $0.70-1.12$ \\
\hline Stage IB & 0.07 & 0.78 & $0.59-1.02$ & Stage IB & 0.04 & 0.78 & $0.61-0.99$ \\
\hline Stage IIA & 0.95 & 0.99 & $0.75-1.32$ & Stage IIA & 0.68 & 0.95 & $0.74-1.22$ \\
\hline Stage IIB & 0.29 & 0.89 & $0.71-1.11$ & Stage IIB & 0.20 & 0.88 & $0.72-1.07$ \\
\hline Stage IIIA & $<0.001$ & 1.66 & $1.39-1.99$ & Stage IIIA & $<0.001$ & 1.53 & $1.30-1.80$ \\
\hline Stage IIIB & $<0.001$ & 3.05 & $2.41-3.87$ & Stage IIIB & $<0.001$ & 2.59 & $2.06-3.26$ \\
\hline
\end{tabular}

OS = overall survival, DFS = disease free survival, $\mathrm{Cl}=$ confidence interval; HR = hazard ratio; UICC = Union for Inter-national Cancer Control.

surgery or not are additionally complicated by the wellestablished discrepancies between clinical and pathological staging [25].

With advances in genomic analysis and targeted therapies, genetic differences even among tumors of the same histological subtype are becoming more significant than ever. A tumor mutation that responds well to available immunotherapies can mean a significant survival benefit that is independent of tumor stage [26, 27]. Developments in the field of cancer immunology have sparked discussions about incorporating tumorbiological characteristics into future staging systems, but so far no actual changes have been implemented.

As secondary findings we determined that female gender and age 65 or younger were significantly independently associated with better outcomes, in concordance with other studies [28, 29]. Additionally, pneumonectomy was a significant independent predictor of better OS and DFS, while segmentectomy and wedge resection were significant independent predictors of worse long-term 

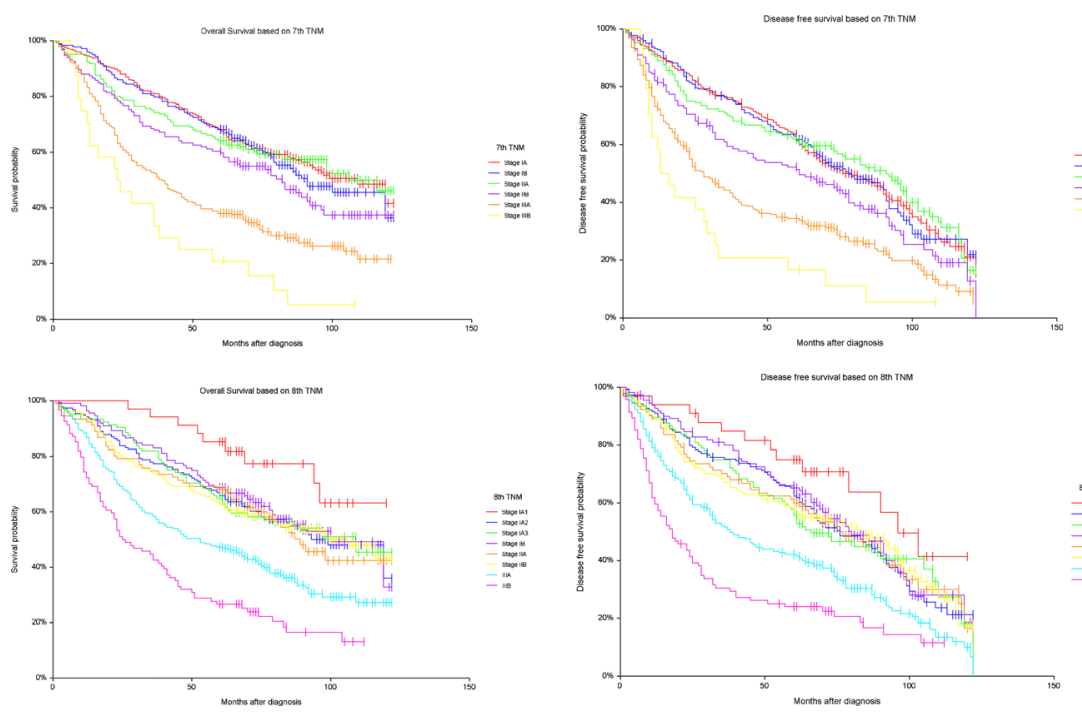

Figure 2: Kaplan-Meier curves with overall survival (OS) and disease free survival (DFS) by stage based on the 7th and 8th editions of TNM respectively. Log rank analysis of OS based on 7th TNM: IA vs. IB $(p=0.6165)$, IB vs. IIA ( $p=0.812)$, IIA vs. IIB $(p=0.085)$, IIB vs. IIIA $(p<0.001)$, IIIA vs. IIIB $(p=0.017)$; OS based on 8th TNM: IA1 vs $1 A 2$ $(p=0.039), I A 2$ vs. IA3 ( $p=0.998), I A 3$ vs. IB $(p=0.681)$, IB vs. IIA ( $p=0.494)$, IIA vs. IIB $(p=0.849)$, IIB vs. IIIA $(p=<0.001)$, IIIA vs. IIIB $(p<0.001)$; DFS based on 7th TNM: IA vs. IB ( $p=0.946)$, IB vs. IIA ( $p=0.630)$, IIA vs. IIB ( $p=0.019)$, IIB vs. IIIA ( $p=0.003)$, IIIA vs. IIIB (0.043); DFS based on 8th TNM: IA1 vs. $1 A 2(p=0.084), I A 2$ vs. IA3 ( $p=0.775), I A 3$ vs. IB ( $p=0.484)$, IB vs. IIA ( $p=0.600)$, IIA vs. IIB $(p=0.997)$, IIB vs. IIIA $(p<0.001)$, IIIA vs. IIIB $(\mathrm{p}<0.001)$.
Table 5: Comparison of neighboring Union for International Cancer Control (UICC) stages: Cox regression analysis after adjusting for gender, surgery, and age.

\begin{tabular}{|c|c|c|c|}
\hline \multirow[b]{2}{*}{ Stage } & \multirow[b]{2}{*}{ p-Value } & \multicolumn{2}{|c|}{ OS based on 7 th edition TNM } \\
\hline & & HR & $95 \% \mathrm{Cl}$ \\
\hline IA vs. IB & $<0.001$ & 0.61 & $0.51-0.73$ \\
\hline IB vs. IIA & $<0.001$ & 0.41 & $0.31-0.54$ \\
\hline IIA vs. IIB & $<0.001$ & 0.27 & $0.20-0.38$ \\
\hline IIB vs. IIIA & $<0.001$ & 0.24 & $0.17-0.34$ \\
\hline IIIA vs. IIIB & $<0.001$ & 0.39 & $0.27-0.57$ \\
\hline \multicolumn{4}{|c|}{ OS based on 8th edition TNM } \\
\hline IA1 vs. $1 \mathrm{~A} 2$ & 0.004 & 0.42 & $0.24-0.75$ \\
\hline IA2 vs. IA3 & $<0.001$ & 0.34 & $0.20-0.59$ \\
\hline IA3 vs. IB & $<0.001$ & 0.29 & $0.17-0.48$ \\
\hline IB vs. IIA & $<0.001$ & 0.22 & $0.14-0.36$ \\
\hline IIA vs. IIB & $<0.001$ & 0.22 & $0.15-0.33$ \\
\hline IIB vs. IIIA & $<0.001$ & 0.20 & $0.14-0.27$ \\
\hline IIIA vs. IIIB & $<0.001$ & 0.33 & $0.26-0.42$ \\
\hline \multicolumn{4}{|c|}{ DFS based on 7 th edition TNM } \\
\hline IA vs. IB & $<0.001$ & 0.66 & $0.56-0.78$ \\
\hline IB vs. IIA & $<0.001$ & 0.46 & $0.36-0.59$ \\
\hline IIA vs. IIB & $<0.001$ & 0.31 & $0.23-0.42$ \\
\hline IIB vs. IIIA & $<0.001$ & 0.30 & $0.21-0.42$ \\
\hline IIIA vs. IIIB & $<0.001$ & 0.46 & $0.32-0.66$ \\
\hline \multicolumn{4}{|c|}{ DFS based on 8th edition TNM } \\
\hline IA1 vs. $1 \mathrm{~A} 2$ & 0.015 & 0.55 & $0.34-0.89$ \\
\hline IA2 vs. IA3 & $<0.001$ & 0.44 & $0.28-0.70$ \\
\hline IA3 vs. IB & $<0.001$ & 0.39 & $0.25-0.61$ \\
\hline IB vs. IIA & $<0.001$ & 0.30 & $0.20-0.46$ \\
\hline IIA vs. IIB & $<0.001$ & 0.29 & $0.20-0.41$ \\
\hline IIB vs. IIIA & $<0.001$ & 0.25 & $0.19-0.34$ \\
\hline IIIA vs. IIIB & $<0.001$ & 0.39 & $0.31-0.48$ \\
\hline
\end{tabular}

$\mathrm{OS}=$ overall survival; $\mathrm{DFS}=$ disease free survival; $\mathrm{HR}=$ hazard ratio; $\mathrm{Cl}=$ confidence interval. outcome. These findings, however, must be interpreted in the context of the fact that lobectomy or bilobectomy is our standard approach $(79.2 \%$ in our cohort). The seeming benefit of pneumonectomy is likely an artifact due to patient selection. Not all patients who can tolerate lobectomy can tolerate pneumonectomy, meaning that only healthier patients can even be considered for pneumonectomy. Moreover, pneumonectomies are associated with significantly greater perioperative mortality, and the fact that we excluded patients who died within 30 days of surgery may also help explain the seemingly better outcomes for patients with pneumonectomies. Due to the enormous volume loss that pneumonectomy entails it cannot be recommended for peripheral tumors.

Interestingly, histology did not have a significant impact on outcome. Although patients with large cell carcinomas had worse five-year OS (39.5\%), the five-year survival rates for patients with adenocarcinomas and squamous cell carcinomas were nearly the same ( 47.9 vs $47.0 \%)$. Although tumor free resection margins had a significant positive impact on OS and DFS in the univariate analysis, this effect was not a significant independent predictor in the multivariate analysis. This is somewhat surprising but may have to do with the small number of patients with positive resection margins (5.3\%). It may also be that the effect was small enough to be outweighed by the more powerful effects of the other factors discussed above.

This study incorporates a large number of patients followed until death or for a minimum of five years following surgery. It is also one of the only broader investigations of the 8th edition of the TNM classification in a European population. However, it has some limitations. As 
in all retrospective studies a certain degree of bias is unavoidable. Additionally, it was not possible to incorporate data on comorbidities, which for obvious reasons can affect OS, but may potentially affect DFS as well because of decisions to forgo adjuvant treatment for example. We were able to partially account for comorbidity and nononcological causes of death by excluding patients who died within 30 day of surgery. While not a limitation per se, it is also important to underscore that the data applies only to surgically treated patients.

Finally, although the 8th edition seems to be slightly better at predicting OS and DFS the difference is small. The differences of all neighboring survival curves were significant, but in most cases only after controlling for the identified covariates of gender, age, and surgery type. Although tumor stage influences outcome in surgical patients with NSCLC it is only one prognostic factor of many. In summary, this analysis validates the revised 8th edition stage groupings for the TNM classification for NSCLC in a large European cohort of surgical patients. The significant differences in outcomes between stages IA1 and IA 2 and IA 3 support the 8th edition creation of these new categories.

Acknowledgments: Thank you to Ms. Stephanie Krüger for her assistance in the data management.

Research funding: Authors state no funding involved.

Author contributions: All authors have accepted responsibility for the entire content of this manuscript and approved its submission. Samantha Taber: Conceptualization, Methodology, Project administration, Data Management and Statistics, Writing - original draft. Joachim Pfannschmidt: Conceptualization, Data curation, Formal analysis, Validation, Writing - review and editing. Competing interests: Authors state no conflict of interest. Informed consent and Ethical approval: The institutional review board waived the need for registration because all data had been gathered for internal quality control, and all patients had previously given their informed consent to have their data used for research purposes. The conducted research is not related to either human or animals use. The research related to human use complies with all the relevant national regulations, institutional policies and was performed in accordance the tenets of the Helsinki Declaration.

\section{References}

1. Van Schil PE, Rami-Porta R, Asamura H. The 8th TNM edition for lung cancer: a critical analysis. Ann Transl Med 2018;6:87-87.
2. Detterbeck FC. The eighth edition TNM stage classification for lung cancer: what does it mean on main street?. J Thorac Cardiovasc Surg 2018;155:356-9.

3. Detterbeck FC, Boffa DJ, Kim AW, Tanoue LT. The 8th edition lung cancer stage classification. Chest 2017;151:193-3.

4. Asamura H, Chansky K, Crowley J, Goldstraw P, Rusch VW, Vansteenkiste JF, et al. The international association for the study of lung cancer lung cancer staging project. J Thorac Oncol 2015; 10:1675-84.

5. Rami-Porta R, Bolejack V, Giroux DJ, Chansky K, Crowley J, Asamura $\mathrm{H}$, et al. The IASLC lung cancer staging project: the new database to inform the eighth edition of the TNM classification of lung cancer. J Thorac Oncol 2014;9:1618-24.

6. Lim W, Ridge CA, Nicholson AG, Mirsadraee S. The 8th lung cancer TNM classification and clinical staging system: review of the changes and clinical implications. Quant Imag Med Surg 2018;8: 709-18.

7. Travis WD, Asamura H, Bankier AA, Beasley MB, Detterbeck F, Flieder DB, et al. The IASLC lung cancer staging project: proposals for coding $T$ categories for subsolid nodules and assessment of tumor size in part-solid tumors in the forthcoming eighth edition of the TNM classification of lung cancer. J Thorac Oncol 2016;11: 1204-23.

8. Goldstraw P, Crowley J, Chansky K, Giroux DJ, Groome PA, RamiPorta R, et al. The IASLC lung cancer staging project: proposals for the revision of the TNM stage groupings in the forthcoming (7th) edition of the TNM classification of malignant tumours. J Thorac Oncol 2007;2:706-14.

9. Chansky K, Detterbeck FC, Nicholson AG, Rusch VW, Vallières E, Groome P, et al. The IASLC lung cancer staging Project: external validation of the revision of the TNM stage groupings in the eighth edition of the TNM classification of lung cancer. J Thorac Oncol 2017;12:1109-21.

10. Jung HS, Lee JG, Lee CY, Kim DJ, Chung KY. Validation of the T descriptor in the new 8th TNM classification for non-small cell lung cancer. J Thorac Dis 2018;10:162-7.

11. Sui X, Jiang W, Chen H, Yang F, Wang J, Wang Q. Validation of the stage groupings in the 8th edition of the TNM classification for lung cancer. J Thorac Oncol 2017;12:1679-86.

12. Chen K, Chen H, Yang F, Sui X, Li X, Wang J. Validation of the 8th edition of the TNM staging system for lung cancer in 2043 surgically treated patients with non-small-cell lung cancer. Clin Lung Canc 2017;18:e457-66.

13. Yun JK, Lee GD, Kim HR, Kim YH, Kim DK, Park SI, et al. Validation of the 8th edition of the TNM staging system in 3,950 patients with surgically resected non-small cell lung cancer. J Thorac Dis 2019;11:2955-64.

14. Schabath MB, Cress WD, Muñoz-Antonia T. Racial and ethnic differences in the epidemiology and genomics of lung cancer. Canc Cont 2016;23:338-46.

15. Zhou W, Christiani DC. East meets West: ethnic differences in epidemiology and clinical behaviors of lung cancer between East Asians and Caucasians. Chin J Canc 2011;30:287-92.

16. Neppl C, Keller MD, Scherz A, Dorn P, Schmid RA, Zlobec I, et al. Comparison of the 7th and 8th edition of the UICC/AJCC TNM staging system in primary resected squamous cell carcinomas of the lunga single center analysis of 354 cases. Front Med 2019;6:196.

17. Blaauwgeers H, Damhuis R, Lissenberg-Witte BI, de Langen AJ, Senan S, Thunnissen E. A population-based study of outcomes in surgically resected T3NO non-small cell lung cancer in The 
Netherlands, defined using TNM-7 and TNM-8; justification of changes and an argument to incorporate histology in the staging algorithm. J Thorac Oncol 2019;14: 459-67.

18. Detterbeck FC, Chansky K, Groome P, Bolejack V, Crowley J, Shemanski L, et al. The IASLC lung cancer staging project: methodology and validation used in the development of proposals for revision of the stage classification of NSCLC in the forthcoming (8th) edition of the TNM classification of lung cancer. J Thorac Oncol 2016;11:1433-46.

19. Okami J, Shintani Y, Okumura M, Ito H, Ohtsuka T, Toyooka S, et al. Demographics, safety and quality, and prognostic information in both the seventh and eighth editions of the TNM classification in 18,973 surgical cases of the Japanese joint committee of lung cancer registry database in 2010. J Thorac Oncol 2019;14:212-22.

20. Kameyama K, Takahashi M, Ohata K, Igai H, Yamashina A, Matsuoka T, et al. Evaluation of the new TNM staging system proposed by the international association for the study of lung cancer at a single institution. J Thorac Cardiovasc Surg 2009;137: 1180-4.

21. Rena O, Massera F, Robustellini M, Papalia E, Delfanti R, Lisi E, et al. Use of the proposals of the international association for the study of lung cancer in the forthcoming edition of lung cancer staging system to predict long-term prognosis of operated patients. Canc J 2010;16:176-81.

22. Hung JJ, Wu YC, Chou TY, Jeng WJ, Yeh YC, Hsu WH. Adjuvant chemotherapy improves the probability of freedom from recurrence in patients with resected stage IB lung adenocarcinoma. Ann Thorac Surg 2016;101:1346-53.
23. Morgensztern D, Du L, Waqar SN, Patel A, Samson P, Devarakonda S, et al. Adjuvant chemotherapy for patients with T2NOMO NSCLC. J Thorac Oncol 2016;11:1729-35.

24. Strauss GM, Wang XF, Maddaus M, Johnstone D, Johnson E, Harpole D, et al. Adjuvant chemotherapy (AC) in stage IB nonsmall cell lung cancer (NSCLC): long-term follow-up of Cancer and Leukemia Group B (CALGB) 9633. J Clin Oncol 2011;29:7015-7015.

25. D'Cunha J, Herndon JE, Herzan DL, Patterson GA, Kohman LJ, Harpole DH, et al. Poor correspondence between clinical and pathologic staging in stage 1 non-small cell lung cancer: results from CALGB 9761, a prospective trial. Lung Canc 2005; 48:241-6.

26. Zhou C, Wu YL, Chen G, Feng J, Liu XQ, Wang C, et al. Final overall survival results from a randomised, phase III study of erlotinib versus chemotherapy as first-line treatment of EGFR mutationpositive advanced non-small-cell lung cancer (OPTIMAL, CTONG0802). Ann Oncol 2015;26:1877-83.

27. Thomas R, Weihua Z. Rethink of EGFR in cancer with its kinase independent function on board. Front Oncol 2019;9:800.

28. Visbal AL, Williams BA, Nichols FC, Marks RS, Jett JR, Aubry MC, et al. Gender differences in non-small-cell lung cancer survival: an analysis of 4,618 patients diagnosed between 1997 and 2002. Ann Thorac Surg 2004;78:209-15.

29. Tas F, Ciftci R, Kilic L, Karabulunt S. Age is a prognostic factor affecting survival in lung cancer patients. Oncol Lett 2013;6: 1507-13.

Supplementary Material: The online version of this article offers supplementary material (https://doi.org/10.1515/iss-2020-0010). 